\title{
Digitization in B2B Buying and Selling
}

\author{
Nils Van den Steen \\ Ghent University \\ nils.vandensteen@ugent.be \\ Steve Muylle \\ Vlerick Business School, Ghent University \\ steve.muylle@vlerick.com
}

\author{
Amit Basu \\ Cox School of Business \\ abasu@mail.cox.smu.edu \\ Willem Standaert \\ HEC Liège - University of Liège \\ willem.standaert@uliege.be
}

\begin{abstract}
Business-to-business transactions include several processes that can be digitized by buyers and suppliers. While prior studies have examined the performance impacts of using digital technologies, they have not investigated the alignment of such digitization between transacting parties. In this paper, we empirically examine the use of different market-based digital technologies by buyers and suppliers for these processes, and analyze the extent to which the digitization of different processes is aligned between transacting buyers and suppliers. Our field study is based on surveys of transacting agents in 174 buyersupplier dyads about their use of digital technologies. The results indicate that there are misalignments for some processes in both the specific digital technologies buyers and suppliers use, and in the extent to which each of them uses digital technologies. By addressing these misalignments, buyers and suppliers could potentially realize greater benefits from digitized transaction processes.
\end{abstract}

\section{Introduction}

A variety of digital technologies can be used to implement business-to-business (B2B) transactions, ranging from market-based technologies such as email communication, websites, online marketplaces, social media, and mobile apps, to integrated systems connecting buyer and supplier firms (e.g., vendormanaged inventory systems). Integrated systems are primarily applicable in the case of repeat purchases of a given product by a given buyer from a given supplier, while market-based technologies can be used by buyers and suppliers for both new and repeat transactions.
The potential performance benefits of using marketbased digital technologies in B2B transactions have been well documented $[1,2]$. Yet, research by Gartner [3] points to the importance of considering the bilateral nature of B2B transactions. They suggest that even though digital and offline interactions have become parallel experiences across all stages of the transaction, "the onus is on sales leaders to make the purchase process easier" by better understanding how customers make purchases so that they can "give customers an entry point on their own terms" and "customers can progress to a purchase decision effectively and efficiently".

However, little is known about the use of specific market-based digital technologies by buyers and suppliers to support each of the different processes in business-to-business transactions. Also, given the bilateral nature of most business transactions, the performance impact of a firm's digitization of transaction processes might be affected by the alignment of their digitization efforts with those of the transacting counterparties. For instance, if a supplier firm posts information about a certain product on its website but the buyer firm that eventually purchases that product from the supplier does not use the supplier website to acquire product information, then the supplier firm's website provides little value for that process in that transaction. Conversely, the buyer may spend more time and effort than necessary to acquire the product information using either a different digital technology or an offline channel. As such, if these misalignments exist, they might keep both transacting firms from realizing greater benefits from digitizing their transaction processes.

Business transactions are typically comprised of the following processes: search, authentication, valuation, payment, logistics and customer service [4]. However, not all firms digitize all their transaction processes 
concurrently, particularly if they are small or mediumsized [5]. If so, they have to decide which processes to digitize and which technologies to use for that purpose. As a result, buyers and suppliers interacting in B2B transactions may possibly have significant misalignments in their digitization priorities and efforts. These misalignments are more likely to occur when using market-based digital technologies than when using integrated systems, due to the latter commonly requiring intense initial coordination between the transacting parties. As such, the focus of this paper is on the use of market-based technologies in the various processes comprising B2B transactions. In particular, we address two research questions: (1) Which marketbased digital technologies do buyers and suppliers use for the different processes in B2B transactions? And (2) For which processes in B2B transactions are buyers and suppliers misaligned in their use of digital technologies?

In order to address these two research questions, we conducted a field study of 348 transacting agents in 174 buyer-supplier dyads, examining their use of different market-based digital technologies for the processes in a specific B2B transaction. Buyers were surveyed on their use of market-based digital technologies that were supported by suppliers in the transaction processes (e.g., the buyer visiting the website of the supplier). ${ }^{1}$

This work contributes to the literature by showing which specific digital technologies firms use in support of the different transaction processes. This study also identifies misalignments in the use of specific digital technologies by buyers and suppliers for some processes, and in the extent to which they both digitize certain processes. An important feature of our study is the use of a dyadic approach rather than the monadic approach of most past studies on the use of nonintegrated systems for B2B transactions [e.g., 6-8]. In addition, we add to the thin pool of research using a pairmatched empirical dyadic design over a singlesupplier/multiple buyer dyadic design [e.g., 9].

This paper is organized in 6 sections. In section 2, we discuss related work. Section 3 lays out the research framework and in section 4 we describe the design of our empirical study. The results of our empirical analysis are presented in section 5. Finally, in section 6, we discuss the implications of our work, its limitations, and some avenues for future research.

\section{Literature review}

Two general streams of work can be identified in the literature on the use of market-based digital

\footnotetext{
${ }^{1}$ While firms can also set up Web portals to post their purchase needs, very few such instances were found in our data set.
}

technologies for B2B transactions: studies focused on the firm in the role of a buyer or a supplier, and studies on online B2B marketplaces.

In the first stream, three sets of studies can be identified. The first set takes a buyer perspective and investigates how firms can digitize their procurement activities. For example, Mishra et al. [7] examined the impact of internet use across two stages of the procurement process on procurement performance. In a later study, Mishra, Devaraj and Vaidyanathan [10] looked at the impact of a firm's use of digital technologies on procurement performance. Second, some studies take a supplier perspective and investigate how firms can digitize their sales activities. For instance, Chakraborty, Srivastava and Warren [11] and Rodriguez, Peterson and Krishnan [12] investigated the impact of firms using specific digital technologies in B2B selling such as websites or social media. The third set of studies looks at how a single firm digitizes both procurement and sales activities, and how that impacts performance $[6,8]$.

The second stream of studies focuses specifically on the concept, use and design of online B2B marketplaces. Zhu, Kraemer, Gurbaxani and Xu [13, p.524] discussed how the move from using proprietary or less open interorganizational systems to using the open-standard Internet enables firms to "search for and connect to unknown firms that also support open standards", which in turn facilitates the expansion into new markets and reaching new business partners. Overby and Jap [14] found that following the introduction of electronic channels, both buyers and suppliers use electronic channels for some transactions involving low product quality uncertainty, while continuing to use physical channels for products with high quality uncertainty. Yao et al. [2, p.844] found that internet-based electronic markets, defined as "transaction systems featuring multilateral relationships enabled by the internet open protocol and standards", outperform private Electronic Data Interchange (EDI)-based interorganizational systems in terms of fulfillment performance. Yoo, Choudhary and Mukhopadhyay [15] focused on the consequences of different ownership structures (buyerowned, supplier-owned, and 3rd party owned) of B2B marketplaces, and Zhou and Zhu [16] studied the effect of varying degrees of information transparency among B2B marketplace participants. In addition, there is work on the impact of network effects on pricing and trading decisions in multi-sided B2B platforms [17].

It is worthwhile noting that while several studies have taken a dyadic perspective to analyze buyer- 
supplier interactions, their focus has been on the use of digital technologies to integrate processes and promote interorganizational collaboration [e.g., 18].

In summary, while prior studies have examined how the use of digital market-based technologies for both buying and selling impacts performance, little is known about which specific digital technologies firms use for each of the different processes in these B2B transactions or the extent to which there are misalignments in the use by transacting parties.

\section{Research framework}

In this section, we describe the processes involved in B2B transactions, some key digital technologies that are used in support of these processes, and the potential for misalignment.

\subsection{B2B transaction processes}

Given the bilateral nature of most B2B transactions, it is useful to characterize such transactions in terms of component processes that are relevant to both parties. Kambil and van Heck [19, p.3] defined a set of trade processes that are "required in all transactions of goods and services." These processes involve search, authentication, valuation, payment, logistics, and customer service, and can be organized in two sets, precommitment and post-commitment processes [4] (see Table 1). One key difference between the two sets of processes is that for the pre-commitment processes each firm potentially considers multiple transactions and/or multiple counterparties while post-commitment processes take place between a given buyer and a given supplier for a given transaction. In addition, in the case of repeat transactions, the pre-commitment processes often become redundant.

While each of these processes needs to be supported for a transaction to be completed, it is important to note that they are not strictly sequential, and that buyers and/or suppliers may iterate through them multiple times. For example, before a buyer completes payment with a specific supplier it could have identified and authenticated multiple suppliers and their products, and have had price negotiations with some of them.

\subsection{B2B transaction processes digitization}

For the pre-commitment processes in B2B transactions, the focus of buyers is on information discovery, "the process whereby buyers search for product alternatives, compare the offerings, and then choose the desired products from among suppliers" [2, p.844]. In this setting, the use and support of mechanisms that can reduce search and coordination costs across a possibly broad range of options, will be preferred over integrated solutions that restrict options due to lock-in [20]. Overby and Jap [14] and Zhou and Zhu [16] have shown the value of using online B2B marketplaces and portals for this purpose, but other market-based digital technologies such as email, supplier (E-commerce) websites [11], social media [12], and mobile apps can also play an important role in these pre-commitment processes.

For the post-commitment processes, the focus of the transacting parties is on optimizing transaction

Table 1. B2B transaction processes

\begin{tabular}{|c|l|l|}
\hline \multirow{4}{*}{$\begin{array}{c}\text { Pre-commitment } \\
\text { processes }\end{array}$} & Firm search & Finding a relevant counterparty for a B2B transaction. \\
\cline { 2 - 3 } & Product search & Finding a relevant product for a B2B transaction \\
\cline { 2 - 3 } & Firm authentication & $\begin{array}{l}\text { Verifying the trustworthiness and capabilities of the relevant } \\
\text { parties. }\end{array}$ \\
\cline { 2 - 3 } & Product authentication & Verifying the quality and features of the product. \\
\cline { 2 - 3 } & Valuation & $\begin{array}{l}\text { Determining the price for the product through either static or } \\
\text { dynamic mechanisms. }\end{array}$ \\
\hline \multirow{4}{*}{$\begin{array}{c}\text { Post-commitment } \\
\text { processes }\end{array}$} & Payment & $\begin{array}{l}\text { Ensuring the settlement of the payment involved in the } \\
\text { exchange. }\end{array}$ \\
\cline { 2 - 3 } & Logistics & $\begin{array}{l}\text { Specifying and coordinating the movement of products and } \\
\text { resources within and between relevant parties. }\end{array}$ \\
\cline { 2 - 3 } & Customer service & $\begin{array}{l}\text { Facilitating effective use of the product; organizing and } \\
\text { handling dispute resolution services. }\end{array}$ \\
\hline
\end{tabular}


processing, "the execution of transactions through the exchange of appropriate documents and remittances between buyers and suppliers" [2, p.844]. For repeat or scheduled transactions of standard items between firms that have established buyer-supplier relationships, these processes can be implemented using integrated solutions [21]. However, they can also be supported by market-based digital technologies, especially for firsttime, new or ad hoc transactions between two firms.

The extent to which processes in B2B transactions are digitized can vary between buyers and suppliers [4]. Moreover, firms can use both offline and online mechanisms in support of a specific process [4, 22]. This can result in a situation where the use of digital technologies by buyers and suppliers for a particular transaction process is misaligned, and the full potential performance benefits of digitization are not actualized. Consider a buyer that relied primarily on email and offline communication to find and authenticate a particular product before purchasing it from a particular supplier. In the case of this transaction, all product related content that the supplier produced and posted on its social media pages had no direct impact on the completion of the transaction, while the supplier did put effort into it. Moreover, the buyer could have possibly saved time by directly looking on social media for product information instead of using other mechanisms. In this case, both the buyer and supplier could have obtained greater benefits if their use of digital technologies had been more aligned.

\section{Empirical Study}

In this section we describe the data collection, the data set, and the measurement instrument used in our empirical study.

\subsection{Data collection}

In order to compare the use of digital technologies by buyers and suppliers in a specific B2B transaction, we designed a dyadic study investigating both the buyer and supplier in specific transactions instead of a monadic design that would cover only one side of the transaction. In addition, to eliminate "the concern of reduced variance with respect to the singlesupplier/multiple buyer dyadic designs" [9, p.11] we collected a pair-matched sample of distinct buyersupplier dyads.

To identify these buyer-supplier dyads, we contacted senior executives at firms in different industries in Belgium, and asked them to identify a recent purchase of a new product. We then asked them to introduce us to a senior executive at the supplier firm that provided the product. Both the buyer and supplier executives were asked to identify a transaction agent who was knowledgeable about the respective firm's digitization for that particular transaction. Both organizations were offered a summary of the study results as an incentive.

The buyer and supplier respondents fulfilled a key role in the buying or sales unit at their respective firms, making them appropriate informants for this study and minimizing informant bias. They were assured of the confidentiality of their responses and were requested to complete an online questionnaire to provide their perspective on the transaction.

We contacted 660 respondents at different firms across a set of 330 buyer-supplier dyads. A total of 217 buyer respondents completed the survey (for a response rate of 66 percent); and a total of 206 supplier respondents completed the survey (for a response rate of 62 percent). Excluding the non-matching responses and responses that had missing values resulted in 174 buyersupplier dyads for which we had complete surveys from both the buyer and supplier respondents. These response rates are in line with previous studies employing a similar data collection strategy, and the resulting number of dyads is large relative to those in earlier studies [9, 18].

\subsection{Data characteristics}

The B2B transactions in the dyads involved a variety of products. 79 percent of the transactions involved tangible products (e.g., carbon filters, ink, protective equipment), 13 percent involved services (e.g.,

\section{Table 2. Firm characteristics}

\begin{tabular}{|c|c|c|c|}
\hline Variable & Category & $\underset{\%}{\text { Supplier }}$ & $\begin{array}{c}\text { Buyer } \\
\%\end{array}$ \\
\hline \multicolumn{4}{|l|}{ Industry } \\
\hline & Manufacturing & 45 & 41 \\
\hline & Wholesale & 28 & 12 \\
\hline & Retail & 0 & 13 \\
\hline & Computer/Data & 8 & 2 \\
\hline & $\begin{array}{l}\text { Processing } \\
\text { Construction }\end{array}$ & 1 & 9 \\
\hline & Other & 18 & 23 \\
\hline \multicolumn{4}{|c|}{ Number of Employees } \\
\hline & $0-50$ & 47 & 44 \\
\hline & $51-500$ & 33 & 35 \\
\hline & More than 500 & 20 & 21 \\
\hline \multicolumn{4}{|c|}{ Years in business } \\
\hline & $1-5$ years & 7 & 5 \\
\hline & $6-10$ years & 7 & 5 \\
\hline & $11-20$ years & 16 & 16 \\
\hline & Over 20 years & 70 & 74 \\
\hline
\end{tabular}


accountancy, audit, web design), and 8 percent involved digital goods such as software. Table 2 shows that most suppliers operated in the manufacturing, wholesale or computer/data processing industry, while most of the buyers operated in the manufacturing, retail, or wholesale industry. The majority of both buyer and supplier firms were small to medium sized companies and had been in business for over 20 years.

In order to check whether there was a response bias towards certain types of firms, we compared the firm characteristics of respondent and non-respondent firms. The results indicated no significant differences between the two groups, and therefore nonresponse bias was not a significant issue.

\subsection{Measurement instrument}

The survey that each respondent received was specific to their role as a buyer or supplier in the transaction. We asked buyers about their use of digital technologies to perform the different processes (e.g., using the websites of suppliers to authenticate the quality of their products) and asked suppliers how they used digital technologies in support of these processes (e.g., setting up a website with product information for buyers to find). It is important to note that we do not consider the situation where suppliers use digital technologies to actively identify and contact buyers.

In each dyad, both the buyer and supplier firms were asked to provide information on the extent of digital technology use, regardless of the specific technologies, for each process in the transaction, using a percentage scale adapted from [7]. This was used to calculate the average extent of digitization of each process in the transaction by buyers and suppliers. Then they were asked to indicate the different digital technologies (email, supplier websites, 3rd party owned B2B market places or portals, social media, mobile applications, other) that were used for each process, using binary indicators. Finally, buyers were asked about the use of

Table 3. Differences between buyer and supplier use of digital technologies

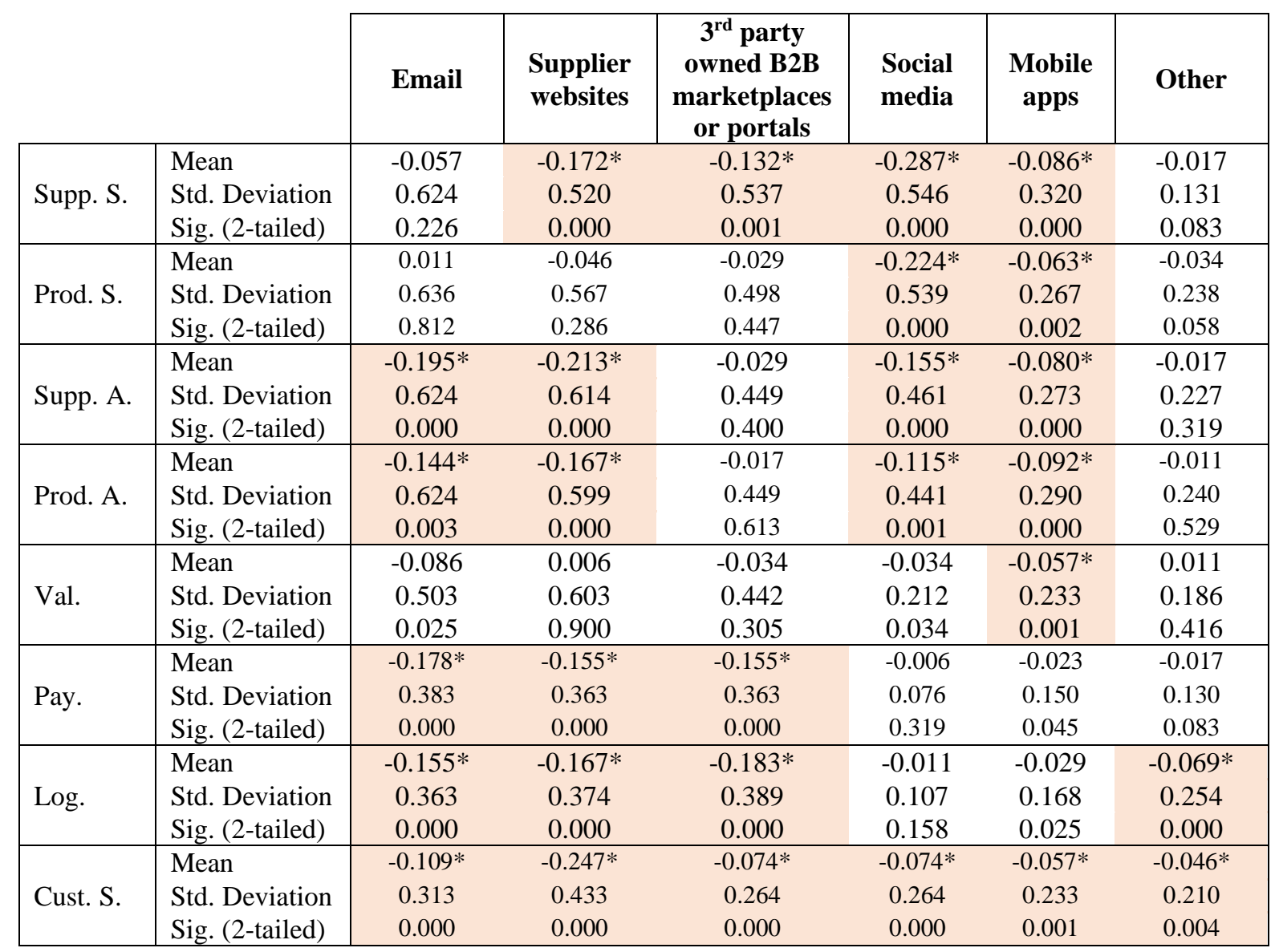

Note: *: $\mathrm{p}<0.00833$ 
each digital technology in each process by allocating a score of 100 across the different technologies for each process. This resulted in a relative score for each technology per process.

\section{Analysis and results}

Our analysis was conducted in two steps. First, we analyzed which technologies were used across dyads by buyers and suppliers for the different processes. Toward this end, we analyzed the number of buyers and suppliers that used each specific technology for each process, based on the binary indicators. The relative frequency provided a view of how widely each technology was used for each process, by buyers and suppliers respectively. Then we tested whether the observed differences between the number of buyers and suppliers that used specific technologies for specific processes were statistically significant. In addition, we examined how important each technology was for each process for the buyers. Therefore, we computed the intensity of the use of each technology in each process for buyers, where intensity referred to the relative extent of use of each technology for each process, by buyers that used that technology for that process. We used the extent of digital technology use that buyers assigned to a process to weigh the relative score they assigned to each technology in support of that process. This weighted measure was the intensity of use of each of the individual digital technologies for each process by the buyer. For example, consider a buyer that assigned a digitization score of 80 percent for the supplier search process, and subsequently allocated a score of 40 percent to e-mail and 60 percent to websites for that process. The intensity of e-mail use by that buyer for supplier search was then $0.8 \times 0.4=32$ percent; and similarly, 48 percent for website use.

Second, we analyzed the use of digital technologies within dyads. To test whether buyers and suppliers were aligned in their use of specific digital technologies for specific processes, we examined whether the binary indicators of buyers and suppliers for each process and technology were significantly correlated. Then, we examined the alignment between buyers and suppliers in their process digitization using their extent of digital technology use for each process, and tested whether the observed differences were statistically significant.

\subsection{Extent of process digitization}

By analyzing patterns across dyads, we gain insight into the use of market-based digital technologies by buyers and suppliers for the different processes in B2B transactions. Figure 1 shows that across all processes the most widely used technologies were the same for both buyers and suppliers. Email and supplier websites were the most widely used digital technologies by both buyers and suppliers for the supplier search, product search, supplier authentication, product authentication, valuation, and customer service processes. Suppliers also used social media and mobile applications for supplier and product search and authentication, but almost none of the buyers used these technologies for any of these processes. Marketplaces/portals and email were the most widely used technologies for the payment process by both buyers and suppliers. For the logistics process, both buyers and suppliers mostly used email.

While figure 1 shows that for each process the most widely used technologies for both buyers and suppliers were the same, it also shows that buyer relative frequency was generally lower than supplier relative frequency. To test whether these observed differences were significant, six two-sided paired t-tests (one for each technology) for each of the eight processes were performed (see Table 3, previous page). The results confirm that for 6 out of the 8 processes, nearly every digital technology was used by more suppliers than buyers at the $0.00833(=0.05 / 6)$ significance level, after correcting for multiple testing. This indicates that suppliers exhibited a wider breadth of use than buyers, i.e. they used more different digital technologies for these processes. Put differently, the digitization efforts of buyers were more focused than those of suppliers. For the other two processes (product search and valuation) buyers and suppliers were generally alike in their breadth of use. It is also worth noting that when social media or mobile applications were offered by suppliers, a significantly smaller number of buyers actually made use of these technologies.

Some interesting patterns also emerge when analyzing the intensity of buyer use. While email was widely used across all transaction processes, it was used intensively for the support of the valuation, logistics and customer service processes (about 50 percent), but less intensively (about 30 percent) for the support of the search and authentication processes. Conversely, while the use of supplier websites was only widespread for the search, authentication and valuation processes, supplier websites were intensively used for each of these processes (about 40 percent). Marketplaces/portals were widely used for the payment process, and they were also used very intensively by buyers (almost 80 percent). When investigating the results per process, we observe that for the search and authentication processes, buyers widely used supplier websites and email. For the valuation process, buyers also widely used both of these technologies, but email more than websites. For the payment process, buyers made the most use of marketplaces/portals, followed by email. Finally, for the 
logistics and customer service processes, buyers mainly used email.

\subsection{Process digitization alignment}

To gain insight into whether buyers and suppliers are aligned in their use of digital technologies within dyads, we analyzed the correlations between buyer and supplier use of specific technologies for specific processes. A significant and positive correlation indicates alignment. Table 4 shows that buyers and suppliers were aligned in their use of specific digital technologies for each of the post-commitment processes, as well as for the valuation process at the $0.00833(=0.05 / 6)$ significance level, after correcting for multiple testing. The alignment of specific technology use for the post-commitment processes could be explained by the nature of these processes, in which buyers and suppliers interact with only one counterparty. However, it seems that buyers and suppliers also have this common understanding of which specific technology to use for the valuation process, a pre-commitment process. This could be due to the iterative nature of many price negotiations forcing both counterparties to agree on which technology to use. Notably, buyers and suppliers do not have this shared understanding with regards to the other pre-commitment processes. This indicates a misalignment in the use of specific digital technologies for the search and authentication processes, which can potentially keep both buyers and sellers from realizing the full benefits of digitizing these processes.

We also examined whether the buyer and supplier within each dyad used digital technologies to the same extent for each of the processes. Figure 2 shows the average extent of digitization of each process in the transaction by buyers and suppliers. We observe that the relative extent of digitization of the different processes by buyers and suppliers was consistent $(r=0.92)$. For example, both buyers and suppliers used digital mechanisms to a greater extent for product search, valuation and payment than for the other processes in B2B transactions. Comparing between buyers and suppliers, supplier digitization was on average higher than buyer digitization for the supplier search, supplier authentication, product authentication and valuation processes. Conversely, we see that for the payment process, buyer digitization was on average slightly higher than supplier digitization. To test whether these differences were significant within dyads we performed eight two-sided paired t-test, one for each process (see Table 5, next page). After correcting for multiple testing, we found that for both the supplier authentication $(\mathrm{p}=0.001)$ and product authentication $(\mathrm{p}=0.004)$ processes digitization by buyers was significantly lower than digitization by suppliers at the $0.00625(=0.05 / 8)$ significance level. Based on the analysis of specific technologies in the previous section, both these misalignments could be explained by

Table 4. Correlation between buyer and supplier use of digital technologies

\begin{tabular}{|c|c|c|c|c|c|c|c|}
\hline & & Email & $\begin{array}{l}\text { Supplier } \\
\text { websites }\end{array}$ & $\begin{array}{c}\mathbf{3}^{\text {rd }} \text { party } \\
\text { owned B2B } \\
\text { marketplaces } \\
\text { or portals }\end{array}$ & $\begin{array}{l}\text { Social } \\
\text { media }\end{array}$ & $\begin{array}{l}\text { Mobile } \\
\text { apps }\end{array}$ & Other \\
\hline \multirow{2}{*}{ Supp. S. } & Pearson Corr. & 0.125 & 0.086 & -0.055 & 0.115 & -0.035 & 1 \\
\hline & Sig. (2-tailed) & 0.100 & 0.260 & 0.469 & 0.132 & 0.642 & \\
\hline \multirow{2}{*}{ Prod. S. } & Pearson Corr. & 0.095 & 0.002 & 0.014 & 0.040 & 0.174 & -0.024 \\
\hline & Sig. (2-tailed) & 0.212 & 0.981 & 0.857 & 0.597 & 0.021 & 0.757 \\
\hline \multirow{2}{*}{ Supp. A. } & Pearson Corr. & 0.186 & 0.102 & 0.142 & 0.184 & I & 0.164 \\
\hline & Sig. (2-tailed) & 0.014 & 0.182 & 0.062 & 0.015 & & 0.031 \\
\hline \multirow{2}{*}{ Prod. A. } & Pearson Corr. & 0.192 & 0.143 & 0.108 & $0.230^{*}$ & I & 0.140 \\
\hline & Sig. (2-tailed) & 0.011 & 0.059 & 0.158 & 0.002 & & 0.066 \\
\hline \multirow{2}{*}{ Val. } & Pearson Corr. & $0.279 *$ & $0.249^{*}$ & 0.182 & $0.234^{*}$ & I & -0.017 \\
\hline & Sig. (2-tailed) & 0.000 & 0.001 & 0.016 & 0.002 & & 0.828 \\
\hline \multirow{2}{*}{ Pay. } & Pearson Corr. & $0.692 *$ & $0.545^{*}$ & $0.731^{*}$ & I & / & $0.886^{*}$ \\
\hline & Sig. (2-tailed) & 0.000 & 0.000 & 0.000 & I & I & 0.000 \\
\hline \multirow{2}{*}{ Log. } & Pearson Corr. & $0.674 *$ & $0.632 *$ & $0.567 *$ & I & $0.527 *$ & $0.759 *$ \\
\hline & Sig. (2-tailed) & 0.000 & 0.000 & 0.000 & l & 0.000 & 0.000 \\
\hline \multirow{2}{*}{ Cust. S. } & Pearson Corr. & $0.512 *$ & $0.537 *$ & $0.649^{*}$ & $0.568^{*}$ & $0.396^{*}$ & $0.690^{*}$ \\
\hline & Sig. (2-tailed) & 0.000 & 0.000 & 0.000 & 0.000 & 0.000 & 0.000 \\
\hline
\end{tabular}

Note: $*: \mathrm{p}<0.00833$ 
suppliers using more email, supplier websites, social media and mobile apps for both these processes.

\section{Table 5. Differences between buyer and supplier process digitization}

\begin{tabular}{|l|c|c|c|}
\cline { 2 - 4 } \multicolumn{1}{c|}{} & Mean & $\begin{array}{c}\text { Std. } \\
\text { Deviation }\end{array}$ & $\begin{array}{c}\text { Sig. (2- } \\
\text { tailed) }\end{array}$ \\
\hline Supp. S. & -7.2 & 42.9 & 0.027 \\
\hline Prod. S. & -0.4 & 39.2 & 0.893 \\
\hline Supp. A. & $-10.7^{*}$ & 41.8 & 0.001 \\
\hline Prod. A. & $-9.1^{*}$ & 41.7 & 0.004 \\
\hline Val. & -2.3 & 44.5 & 0.497 \\
\hline Pay. & 3.7 & 48.3 & 0.318 \\
\hline Log. & 0.5 & 50.4 & 0.895 \\
\hline Cust. S & -0.8 & 41.6 & 0.812 \\
\hline
\end{tabular}

Note: *: $\mathrm{p}<0.00625$

In summary, our results show that across dyads the most widely used technologies for each process were the same for both buyers and suppliers. For 6 out of the 8 transaction processes, suppliers exhibited a wider breadth of use of different technologies than buyers did, as they seemed to focus their efforts on a smaller set of technologies. In line with this result, we also found that each technology that is widely used by buyers for a process, is on average used rather intensively for that process. Our results also show that within dyads, buyers and suppliers were misaligned in their use of specific digital technologies for the search and authentication processes, potentially keeping both from realizing the full benefits of digitizing these processes. Moreover, we also found that while suppliers split their authentication efforts approximately equally between digital and offline channels, buyers conducted authentication mostly offline. As such, the completion of these processes within the transactions might have been more efficient if their digitization efforts had been more aligned. Drawing on our analysis of the specific technologies, we argue this misalignment could be due to suppliers over-using email, supplier websites, social media and mobile apps for supplier and product authentication.

\section{Discussion and conclusion}

The results presented in this study are a first step in a broader effort to understand how the digitization of transaction processes by buyers and suppliers varies and to examine the need to align such digitization efforts among transacting parties.

First, our results shed light on how widely used different digital technologies are for each transaction process. Interestingly, we find that the most widely used technologies are the same for buyers and suppliers. However, buyers focus on a smaller set of technologies for each process than suppliers, with the exception of the product search and valuation processes where buyers and suppliers displayed an equal breadth of use. As such, our results show that depending on the process, buyers and suppliers can have a distinct approach to digitization, which makes it valuable for both scholars and practitioners to conceptualize firm digitization efforts and priorities in terms of these processes.

Second, our results show that within dyads suppliers support certain digital technologies for the search and authentication processes that buyers do not use. In other words, buyer and supplier use of digital technologies is misaligned for these processes. Moreover, we show that suppliers and buyers are significantly different in the extent to which they digitized the authentication processes, with buyers relying significantly less on digital technologies for this process than suppliers. Thus, this study shows that buyers and suppliers are misaligned both in the use of specific digital technologies for the search and authentication processes, and in the extent to which they digitize the latter. As the digitization of processes often requires significant investments, further research will need to determine whether and to what extent these misalignments influence the performance outcomes of digitization.

Third, this study adds a dyadic perspective to a field that is mostly examined by monadic studies [e.g., 6-8], thereby directly taking into account the behavior of the transacting counterparty and accounting for the bilateral nature of business transactions. In addition, by performing the analysis based on a pair-matched sample of distinct buyer-supplier dyads, we also contribute to the small pool of literature in IS using this robust empirical design [e.g., 9] over a single-supplier/multibuyer design.

Several limitations should be kept in mind when interpreting the findings of our study. First, while this work included a rationale for why misaligned digitization between buyers and suppliers could lead to both of them not realizing the full benefits of digitization, we did not measure the impact of such misalignment on performance. A research study to empirically test the impact of digitization misalignment in B2B transactions on performance would be a valuable next step. In addition, by showing the existence of misalignments between buyers and suppliers in the context of business transactions, we add to the call for more dyadic research within the broader context of buyer-supplier interactions. Also, we only collected data on the use of digital technologies by buyers and suppliers in completed B2B transactions. The use of 
digital technologies by suppliers will most likely be the same for uncompleted B2B transactions, as suppliers rarely provide support for market-based technologies for one particular buyer. But this might not be the case for the use of digital technologies by buyers. It would be interesting to examine the differences between digital technology use by buyers and suppliers across both completed and uncompleted transactions. Finally, future research could look into whether the digitization alignment of B2B transactions is impacted by the type of transacted product. Preliminary analysis of this using our dataset suggested that the misalignment for authentication digitization was more prevalent in B2B transactions involving tangible products, compared to the $\mathrm{B} 2 \mathrm{~B}$ transactions involving intangible products or services.

\section{References}

[1] Bakos, J.Y., Reducing buyer search costs: Implications for electronic marketplaces. Management science, 1997. 43(12): p. 1676-1692.

[2] Yao, Y., M. Dresner, and J. Palmer, Private network EDI vs. Internet electronic markets: A direct comparison of fulfillment performance. Management Science, 2009. 55(5): p. 843-852.

[3] Bryan, J., What Sales Should Know About Modern B2B Buyers, in Gartner. 2018.

[4] Basu, A. and S. Muylle, Assessing and enhancing ebusiness processes. Electronic Commerce Research and Applications, 2011. 10(4): p. 437-499.

[5] Dekker, H.C. and A. Van den Abbeele, Organizational learning and interfirm control: The effects of partner search and prior exchange experiences. Organization Science, 2010. 21(6): p. 1233-1250.

[6] Barua, A., P. Konana, A.B. Whinston, and F. Yin, An empirical investigation of net-enabled business value. MIS quarterly, 2004. 28(4): p. 585-620.

[7] Mishra, A.N., P. Konana, and A. Barua, Antecedents and consequences of internet use in procurement: an empirical investigation of US manufacturing firms. Information Systems Research, 2007. 18(1): p. 103-120.

[8] Zhu, K. and K.L. Kraemer, Post-adoption variations in usage and value of e-business by organizations: cross-country evidence from the retail industry. Information systems research, 2005. 16(1): p. 61-84.

[9] Dong, M.C., Y. Fang, and D.W. Straub, The impact of institutional distance on the joint performance of collaborating firms: The role of adaptive interorganizational systems. Information Systems Research, 2017. 28(2): p. 309-331.
[10] Mishra, A.N., S. Devaraj, and G. Vaidyanathan, Capability hierarchy in electronic procurement and procurement process performance: An empirical analysis. Journal of Operations Management, 2013. 31(6): p. 376-390.

[11] Chakraborty, G., P. Srivastava, and D.L. Warren, Understanding corporate B2B web sites' effectiveness from North American and European perspective. Industrial Marketing Management, 2005. 34(5): p. 420-429.

[12] Rodriguez, M., R.M. Peterson, and V. Krishnan, Social media's influence on business-to-business sales performance. Journal of Personal Selling \& Sales Management, 2012. 32(3): p. $365-378$.

[13] Zhu, K., K.L. Kraemer, V. Gurbaxani, and S.X. Xu, Migration to open-standard interorganizational systems: network effects, switching costs, and path dependency. Mis Quarterly, 2006: p. 515-539.

[14] Overby, E. and S. Jap, Electronic and physical market channels: A multiyear investigation in a market for products of uncertain quality. Management Science, 2009. 55(6): p. 940-957.

[15] Yoo, B., V. Choudhary, and T. Mukhopadhyay, Electronic B2B marketplaces with different ownership structures. Management Science, 2007. 53(6): p. 952-961.

[16] Zhou, Z.Z. and K.X. Zhu, The effects of information transparency on suppliers, manufacturers, and consumers in online markets. Marketing Science, 2010. 29(6): p. 11251137.

[17] Li, Z. and T. Pénard, The role of quantitative and qualitative network effects in B2B platform competition. Managerial and Decision Economics, 2014. 35(1): p. 1-19.

[18] Klein, R. and A. Rai, Interfirm Strategic Information Flows in Logistics Supply Chain Relationships. Mis Quarterly, 2009. 33(4): p. 735-762.

[19] Kambil, A. and E. van Heck, Reengineering the Dutch flower auctions: A framework for analyzing exchange organizations. Information Systems Research, 1998. 9(1): p. $1-19$.

[20] Aral, S., Y. Bakos, and E. Brynjolfsson, Information technology, repeated contracts, and the number of suppliers. Management Science, 2017.

[21] Rai, A., P.A. Pavlou, G. Im, and S. Du, Interfirm IT capability profiles and communications for cocreating relational value: evidence from the logistics industry. MIS Quarterly, 2012. 36(1): p. 233-262.

[22] Overby, E., Process virtualization theory and the impact of information technology. Organization science, 2008. 19(2): p. 277-291. 

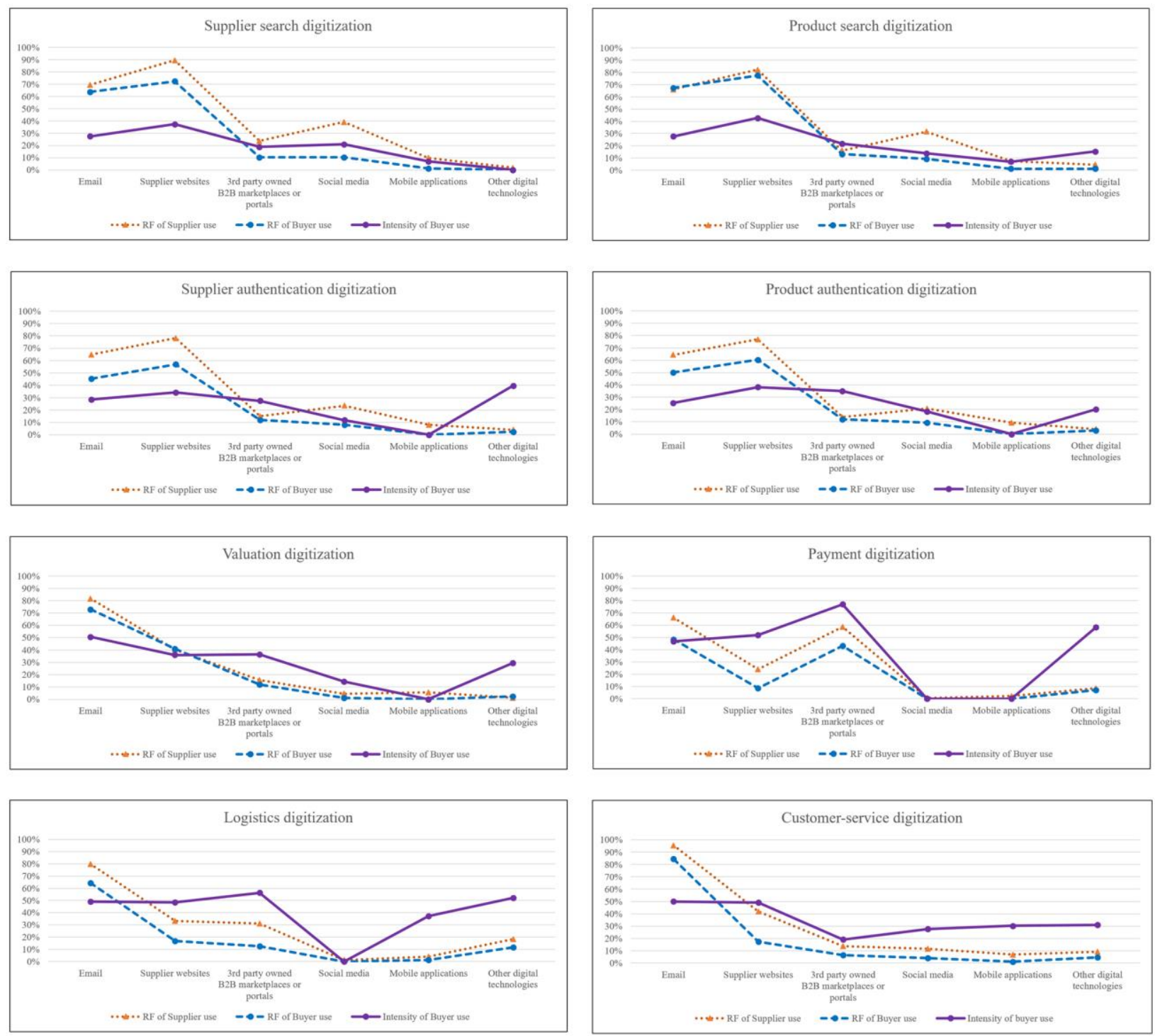

Figure 1. Digital technology use per process

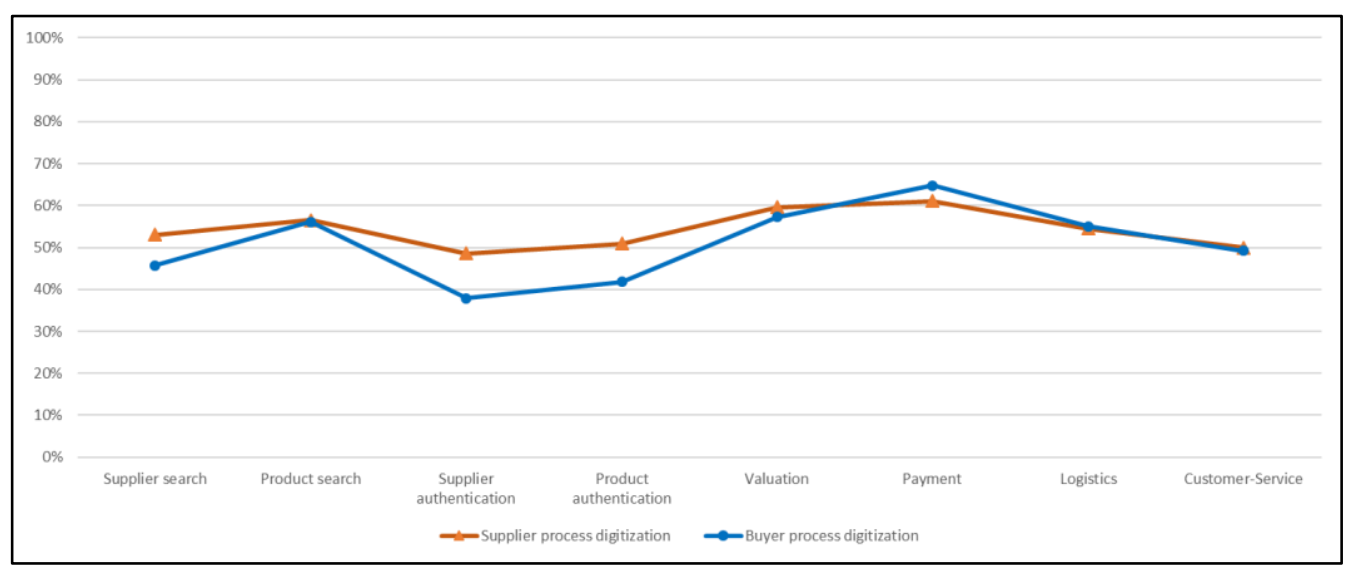

Figure 2. Process digitization alignment 